\title{
Correction to: Effects of acidic catalysts on the microstructure and biological property of sol-gel bioactive glass microspheres
}

\author{
Bo Lei ${ }^{1,2} \cdot$ Xiaofeng Chen ${ }^{1} \cdot$ Young-Hag Koh ${ }^{2}$
}

Published online: 19 October 2021

(C) Springer Science+Business Media, LLC, part of Springer Nature 2021

Correction to: J Sol-Gel Sci Technol (2011) 58:656-663

https://doi.org/10.1007/s10971-011-2441-8
The original version of this article unfortunately contained a mistake in Fig. 4a-b. The correct Fig. 4 is given below.
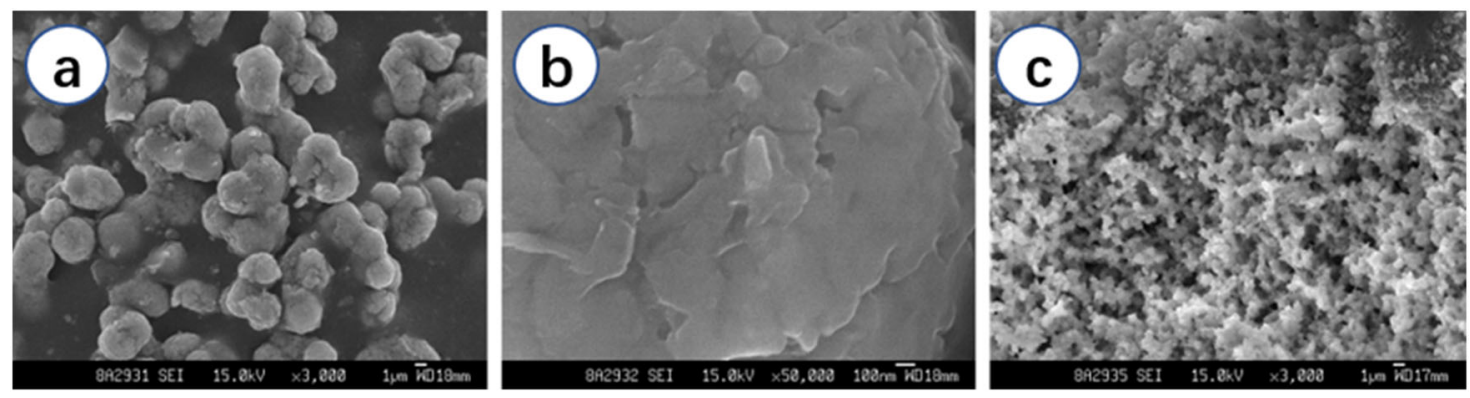

Fig. 4 Micrographs of ABGM1 (a, b) at different magnification and ABGM3 (c)

The original article can be found online at https://doi.org/10.1007/ s10971-011-2441-8.

Bo Lei

leiboaray@yahoo.com.cn

1 Biomedical Engineering Institute, South China University of Technology, Guangzhou 510640, People's Republic of China
Department of Dental Laboratory Science and Engineering, Korea University, Seoul 136703, South Korea 